\title{
Aplikasi Amorik (Animasi Gerak Motorik Tubuh) Sebagai Media Sosialisasi Teknologi Animasi di Lingkungan Pesantren Tahfidz Darussofa Bogor
}

\author{
Darma Rusjdi $^{1}$; Efy Yosrita $^{2}$; Rizqia Cahyaningtyas ${ }^{3}$; Meilia Nur Indah Susanti ${ }^{4}$; Max Teja \\ Ajie Cipta $W^{5}$; Dewi Arianti Wulandari ${ }^{6}$; Herman Bedi Agtriadi ${ }^{7}$; Indrianto ${ }^{8}$ \\ 1, 2, 3, 4, 5, 6, 7,8 Program Studi Teknik Informatika, Sekolah Tinggi Teknik PLN \\ ${ }^{8}$ Indrianto@sttpln.ac.id
}

\begin{abstract}
ABSTRAK
Pengabdian kepada Masyarakat STT-PLN yang dilaksanakan di lingkungan Pesantren yaitu dengan mengajarkan pembuatan animasi menggunakan software Amorik2D. Pelatihan akan diadakan selama 4 hari dimana 2 hari siswa secara langung diberikan tutorial dan praktek sedangkan 2 hari selanjutnya akan dilaksanakan evaluasi terhadap siswa untuk mengetahui sejauh mana mereka menguasai teknik pembuatan animasi dan video animasi. Animasi ialah suatu seni untuk memanipulasi gambar menjadi seolah-olah hidup dan bergerak, yang terdiri dari animasi 2 dimensi maupun 3 dimensi. Animasi 2D membuat benda seolah hidup dengan mengunakan kertas atau komputer. Pada pengabdian ini metode yang digunakan yaitu pertama membentuk model kemudian model tersebut diberi warna, serta dibuat scenario dari model yang telah dibuat. Seluruh proses pembuatannya dari awal hingga akhir dikerjakan di komputer. Pada pelatihan Animasi ini siswa akan diarahkan untuk tujuan pendidikan yang berguna untuk memperjelaskan tentang koordinasi gerak, di mana dalam satu gerakan badan diperlihatkan gerakan tulang-tulang serta sendi tertentu serta hubungannya dengan gerak otot, yang mana otot yang meregang serta otot mana yang melakukan gerakan menarik. Dalam pembuatan video animasi ini pelatihan menggunakan software Amorik2D yang dibuat dan dikembangkan oleh instruktur tim. Aplikasi grafik dan pembuatan video animasi bertujuan agar Siswa mampu membuat gerakan animasi yang baik dan mampu mengelola pembuatan animasi secara beregu. Pesantren Tahfidz Darussofa Desa Ciburayut Bogor bergerak di bidang pendidikan khususnya melatih santri dan calon hafidz dan sesuai dengan perkembangan jaman, para santri dituntut untuk bisa menguasai teknologi informasi yang nanti dapat mendukung dalam proses belajar.
\end{abstract}

Kata Kunci: Teknologi, Animasi, AMORIK, pesantren, Desa Ciburayut

\begin{abstract}
Community Service of STT-PLN carried out in Islamic boarding schools is by teaching the making of animation using Amorik2D software. The training will be held for 4 days where 2 days of students are directly given tutorials and practices while the next 2 days will be carried out an evaluation of students to find out how far they master the techniques of making animation and animated videos. Animation is an art to manipulate images as if they were alive and moving, consisting of twodimensional and three-dimensional animation. $2 D$ animation makes objects live by using paper or computers. In this service the method used is first to form the model then the model is given a color, and a scenario is created from the model that has been made. The entire manufacturing process is done from the beginning to the end of the computer. In this Animation training students will be directed for educational purposes that are useful to explain about motion coordination, where in one body movement the movements of certain bones and joints are shown and their relationship with muscle movement, which muscles are stretched and which muscles make interesting movements In making this animated video the training uses Amorik2D software created and developed by team instructors. The graphics application and the making of animated videos aim to enable students to
\end{abstract}


make good animation movements and be able to manage the creation of animations in teams. Islamic Boarding School Tahfidz Darussofa Ciburayut Bogor Village is engaged in education especially training santri and prospective hafidz and according to the times, the santri are required to be able to master information technology which can later support the learning process.

Keywords: Technology, Animation, AMORIC, pesantren, Desa Ciburayut 


\section{PENDAHULUAN}

Pekembangan dunia komputer yang demikian pesat. Mau tidak mau semua orang harus menerima hal tersebut semua lebaga juga harus menerima itu[1]. Hal ini termasuk pesantren yang mempelajari khusus keagamaan. Pesantren adalah merupakan sebuah pendidikan tradisional yang para siswanya tinggal bersama dan belajar dibawah bimbingan guru yang dikenal dengan sebutan kiai dan mempunyai asrama untuk tempat menginap santri[2]. Pesantren Darussfa merupakan esantren yang menghasilkan lulusan yang beraklak pada Al-Quran. Pesantren Tahfidz Darussofa Bogor bergerak di bidang pendidikan khususnya melatih santri dan calon hafidz dan sesuai dengan perkembangan jaman, para santri dituntut untuk bisa menguasai teknologi informasi yang nanti dapat mendukung dalam proses belajar.

Internet dan teknologi digital secara keseluruhan merevolusi cara dalam memberikan pendidikan baik formal maupun informal, berinteraksi dengan masyarakat, melakukan proses belajar mengajar dan bekerja hampir di seluruh aktivitas sehari-hari. Kemunculan teknologi informasi sesungguhnya bersifat netral, pemanfaatannya bisa menghasilkan dampak positif dan negative, tergantung seberapa bijaksana kita menggunakannya.

Salah satu teknologi yang dimaksud adalah berupa teknologi animasi yang dapat memberikan pandangan hidup pada suatu keadaan yang tidak nyata [3]. Berdasarkan latar belakang tersebut, Tim PKM STT PLN bermaksud mengadakan kegiatan pelatihan penggunaan Aplikasi AMORIK bagi santri dan pengajar Pondok Pesantren Tahfidz Darussofa Desa Ciburayut. Dengan pelatihan tersebut, santri dan pengajar ponpes diharapkan memiliki tambahan keterampilan dalam menggunakan program Animasi berbasis amorik ini. [4]

Pelatihan akan diadakan selama 4 hari dimana 2 hari siswa secara langung diberikan tutorial dan praktek sedangkan 2 hari selanjutnya akan dilaksanakan evaluasi terhadap siswa untuk mengetahui sejauh mana mereka menguasai teknik pembuatan animasi dan video animasi. Animasi ialah suatu seni untuk memanipulasi gambar menjadi seolah-olah hidup dan bergerak, yang terdiri dari animasi 2 dimensi maupun 3 dimensi. Animasi 2D membuat benda seolah hidup dengan mengunakan kertas atau komputer.[5]

Pada pengabdian ini metode yang digunakan yaitu pertama membentuk model kemudian model tersebut diberi warna, serta dibuat scenario dari model yang telah dibuat. Seluruh proses pembuatannya dari awal hingga akhir dikerjakan di komputer.

Pada pelatihan Animasi ini siswa akan diarahkan untuk tujuan pendidikan yang berguna untuk memperjelaskan tentang koordinasi gerak, di mana dalam satu gerakan badan diperlihatkan gerakan tulang-tulang serta sendi tertentu serta hubungannya dengan gerak otot, yang mana otot yang meregang serta otot mana yang melakukan gerakan menarik.

Dalam pembuatan video animasi ini pelatihan menggunakan software Amorik2D yang dibuat dan dikembangkan oleh instruktur tim. Aplikasi grafik dan pembuatan video animasi bertujuan agar Siswa mampu membuat gerakan animasi yang baik dan mampu mengelola pembuatan animasi secara beregu. Pesantren Tahfidz Darussofa Desa Ciburayut Bogor bergerak di bidang pendidikan khususnya melatih santri dan calon hafidz dan sesuai dengan perkembangan jaman, para santri dituntut untuk bisa menguasai teknologi informasi yang nanti dapat mendukung dalam proses belajar. 


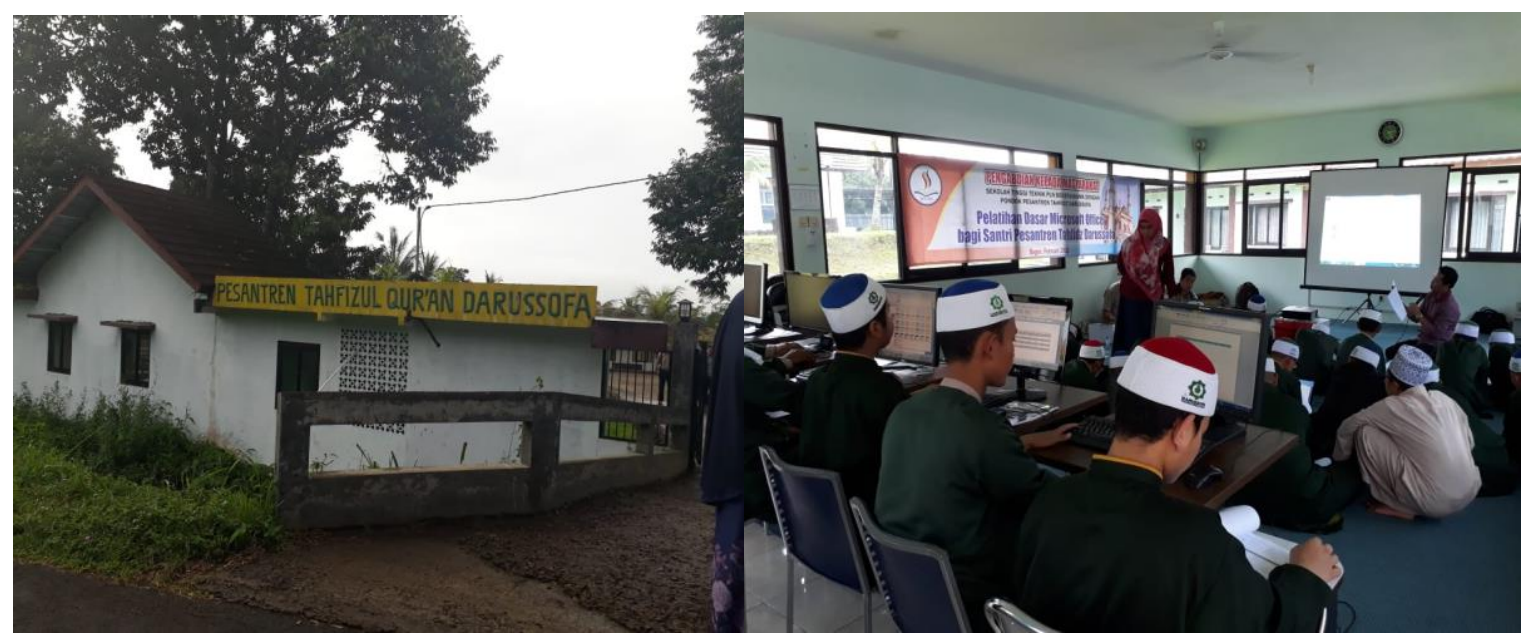

Gambar 1. Ponpes Tahfiz Darussofa

\section{METODE}

Pada pengabdian ini metode yang digunakan yaitu pertama membentuk model kemudian model tersebut diberi warna, serta dibuat scenario dari model yang telah dibuat. Seluruh proses pembuatannya dari awal hingga akhir dikerjakan di computer untuk membuatkan vidio.

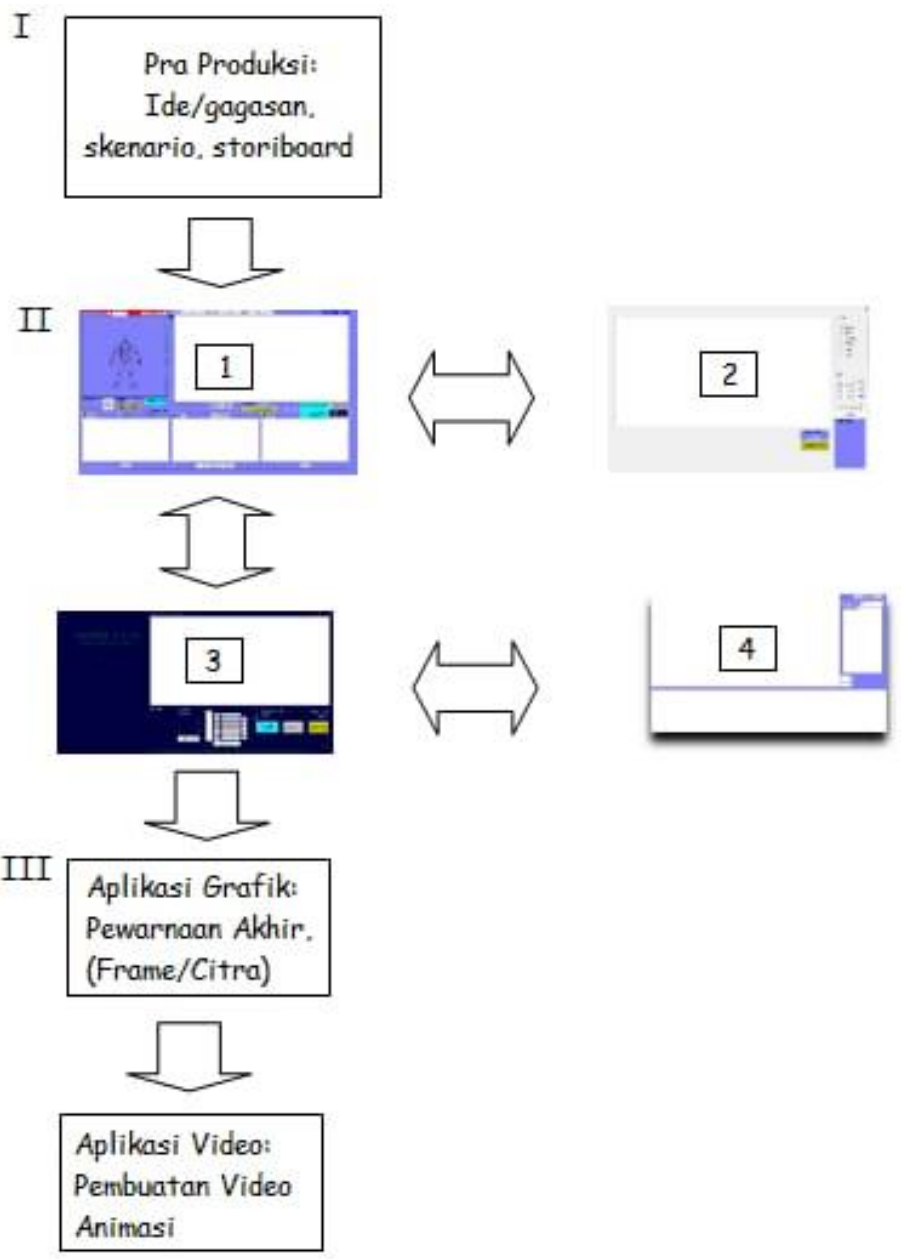


Gambar 2. Metode yang digunakan dalam membuat animasi

\section{HASIL DAN PEMBAHASAN}

Dalam pelatihan ini dilakukan pelatihan ini dilakuakan pembuatan animasi dengan menggunakan AMORIK dengan tampilan sesaui dengan gambar 3. Dibawah ini. Pada gambar 3. Terlihat pada sebelah kiri gambar terdapat gambar orang yang akan dirancang lalu di tempatkan pada layar bagian bawah yang mengikuti urutan dari sebuah gambar yang dinginkan. Pada sebelah kanan atas ada sebuah layar yang dipersiapkan untuk menampilkan animasi yang digabungkan pada layar dibawahnya.

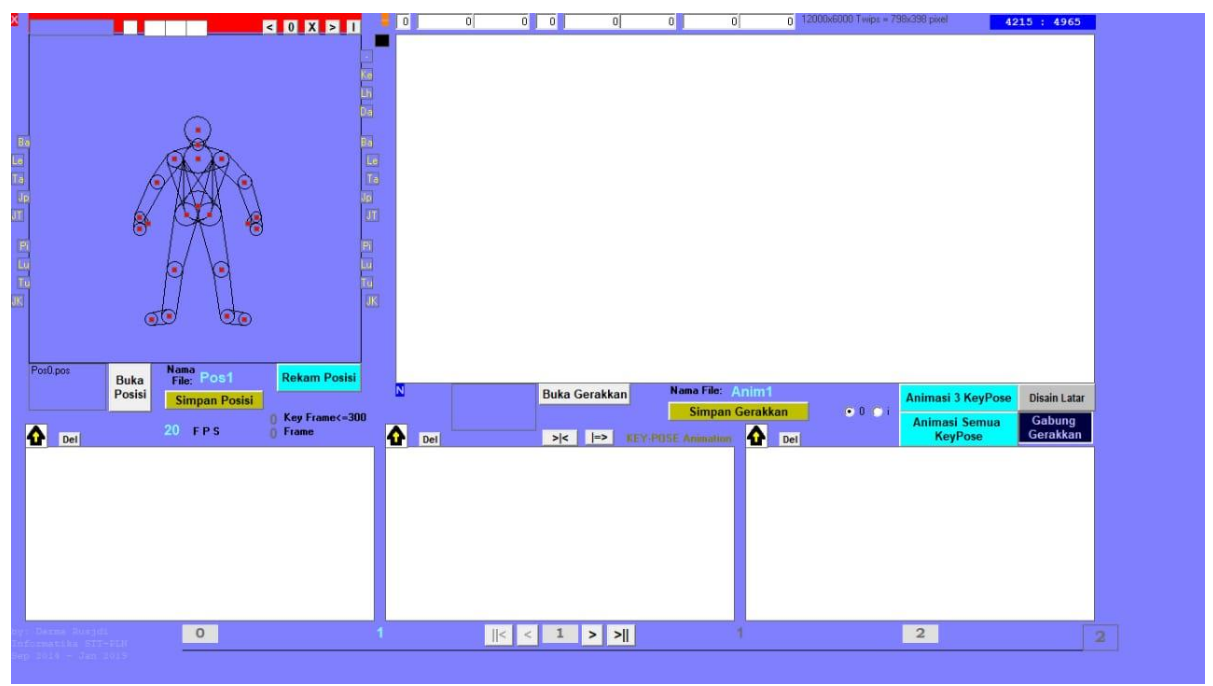

Gambar 3. Gambar Tampilan Amorik

Uji coba yang dilakukan pada anak santri dengan menggunakan komputer yang dipersiapkan oleh panitia. Hal ini dapat dilihat pada kumpulan gambar 4 berikut ini. 


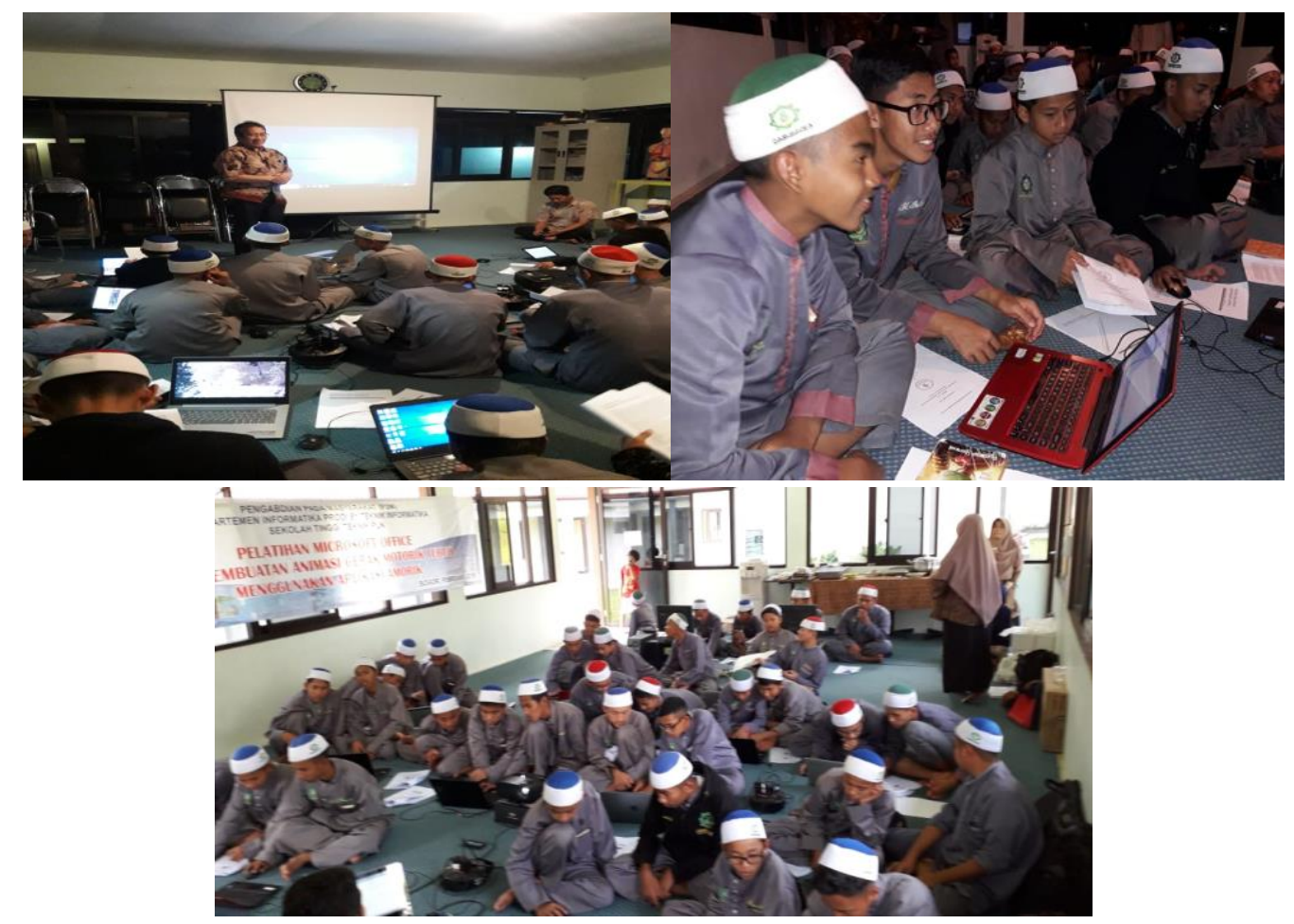

Gambar 3. Gambar foto pelatihan

Untuk mendapatkan hasil yang di inginkan maka diberikan pertanyaan kepada para santri dengan hasil seperti pada tabel1 berikut ini.

Tabel 1. AMORIK

\begin{tabular}{|r|l|r|r|r|}
\hline \hline No. & \multicolumn{1}{|c|}{ Kriteria Utama } & $\begin{array}{c}\text { Pelatihan } \\
\text { Animasi } \\
\text { Amorik }\end{array}$ & $\begin{array}{c}\text { Pelatihan } \\
\text { Animasi } \\
\text { Lainya }\end{array}$ & $\begin{array}{c}\text { Jumlah } \\
\text { peserta }\end{array}$ \\
\hline 1 & Manfaat Software / Program & 13 & 9 & 22 \\
\hline 2 & Mudah Digunakan & 11 & 11 & 22 \\
\hline 3 & Fitur / Inovasi software & 15 & 7 & 22 \\
\hline 4 & Mudah Melakukan Pelatihan Pengguna & 12 & 10 & 22 \\
\hline 5 & Dukungan Pihak Yayasan terhadap Penggunaan Software & 15 & 7 & 22 \\
\hline
\end{tabular}

Terlihat bahwa kebermanfaatan dari AMORIK ini sebesar $59 \%$ dengan menggunakan AMORIK. Hal ini dapat dikatakan bahwa dari 22 santri yang dilakukan pelatihan merasa bahwa AMORIK ini brmanfaat bagi mereka dalam membantu membuat animasi. Dengan menggunakan AMORIK para santri merasa bahwa AMORIK mudah untuk dipergunakan hal ini tercermin dari Tabel 1 diatas bahwa 50\% mudah mneggnakan AMORIK. Fitur yang ditampilkan oleh AMORIK menarik hal ini ercemin dari tabel 1 dengan nilai responden sebesar $68 \%$. Anak - anak santri merasa bahwa pelatihan ini senang melakukan pelatihan ini hal ini sesuai dengan hasil yang didapat sebesar $55 \%$. Pihak yayasan juga mendukung dalam pelatihan ini hal ini dapa terlihat dari tabel dengan nilai $69 \%$ mendukung penggunaan AMORIK dipesantren. 


\section{KESIMPULAN}

Pelatihan animasi gerak motorik tubuh menggunakan software AMORIK pada pesantren darussofa bogor menyimpulkan bahwa aplikasi ini bermanfaat, mempunyai fitur dan inovasi software serta ada dukungan pihak yayasan terhadap penggunaan software, akan tetapi masih dirasa agak sulit dalam penggunaanya serta untuk pelatihan penggunanya agar lebih mendalam lagi supaya para siswa paham. pada kuesioner atau surfei tentang alternatif strategi menyimpulkan bahwa aplikasi ini lebih bagus dari pelatihan atau software animasi laiinya dalam kiteria manfaat software/program, baik dalam fitur dan inovasi software serta dukungan pihak yayasan terhadap penggunaan software. akan tetapi dinilai lebih baik dari alpikasi animasi lainnya dalam kemudahan penggunaan dan kemudahan dalam pelatihannya.

\section{SARAN}

Supaya pelatihan ini dapat berlanjut dengan menggunakan softaware yang berbeda sehingga bisa tercipta desa binaan dari STT PLN di daerah bogor.

\section{UCAPAN TERIMA KASIH}

Kepada Pihak yang membantu pelaksanan ini berjalan dengan lancar yaitu kepada pimpinan Pesantren Darussofa Bogor. Pimpinan STT-PLN. LPPM STT-PLN.

\section{DAFTAR PUSTAKA}

[1] R. Ruli A. Siregar, H. Sikumbang, I. B. Sangadji, and Indrianto, "KWh Meter Smart Card Model Token For Electrical Energy Monitoring," MATEC Web Conf., vol. 218, p. 03002, 2018.

[2] M. Jamaludin, "Karsa : The journal of Social and Islamic Culture.," J. Soc. Islam. Cult., vol. 20, no. 1, pp. 127-139, 2012.

[3] I. E. Putra, "Teknologi Media Pembelajaran Sejarah Melalui," J. Teknoif, vol. 1, no. 2, pp. 16, 2013.

[4] D. Utami, "Efektifitas Animasi Dalam Pembelajaran," Maj. Ilm. Pembelajaran, vol. 7, no. 1, pp. 44-52, 2011.

[5] Y. Syahfitri, “Teknik Film Animasi Dalam Dunia Komputer," J. SAINTIKOM, vol. 10, no. 3, pp. 213-217, 2011. 